ORNL/TM-2016/88

CRADA/NFE-15-05496

\title{
Adsorption Properties of Lignin-derived Activated Carbon Fibers (LACF)
}

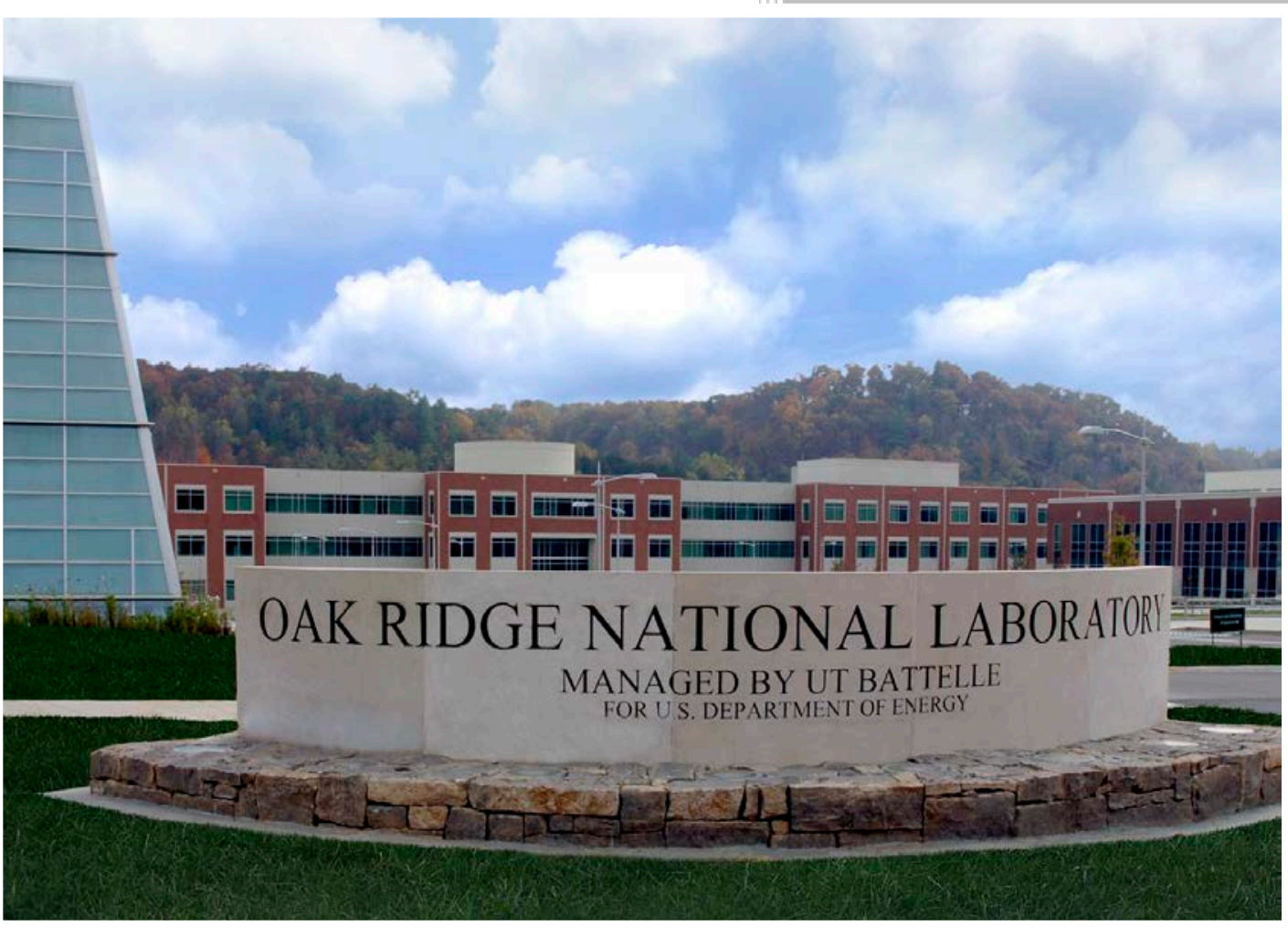

Cristian I Contescu

CRADA FINAL REPORT NFE-15-05496

Approved for Public Release Distribution is Unlimited 


\section{DOCUMENT AVAILABILITY}

Reports produced after January 1, 1996, are generally available free via US Department of Energy (DOE) SciTech Connect.

Website http://www.osti.gov/scitech/

Reports produced before January 1, 1996, may be purchased by members of the public from the following source:

National Technical Information Service

5285 Port Royal Road

Springfield, VA 22161

Telephone 703-605-6000 (1-800-553-6847)

TDD 703-487-4639

Fax 703-605-6900

E-mail info@ntis.gov

Website http://www.ntis.gov/help/ordermethods.aspx

Reports are available to DOE employees, DOE contractors, Energy Technology Data Exchange representatives, and International Nuclear Information System representatives from the following source:

Office of Scientific and Technical Information

PO Box 62

Oak Ridge, TN 37831

Telephone 865-576-8401

Fax 865-576-5728

E-mail reports@osti.gov

Website http://www.osti.gov/contact.html

This report was prepared as an account of work sponsored by an agency of the United States Government. Neither the United States Government nor any agency thereof, nor any of their employees, makes any warranty, express or implied, or assumes any legal liability or responsibility for the accuracy, completeness, or usefulness of any information, apparatus, product, or process disclosed, or represents that its use would not infringe privately owned rights. Reference herein to any specific commercial product, process, or service by trade name, trademark, manufacturer, or otherwise, does not necessarily constitute or imply its endorsement, recommendation, or favoring by the United States Government or any agency thereof. The views and opinions of authors expressed herein do not necessarily state or reflect those of the United States Government or any agency thereof. 
ORNL/TM-2016/88

CRADA/NFE-15-05496

Materials Science and Technology Division

Advanced Manufacturing Office

\title{
Adsorption Properties of Lignin-derived Activated Carbon Fibers (LACF)
}

\author{
Cristian I Contescu \\ Nidia C Gallego \\ Oak Ridge National Laboratory \\ Catherine Thibaud-Erkey, Reddy Karra \\ United Technologies Research Center \\ Date Published: \\ February 25, 2016 \\ Prepared by \\ OAK RIDGE NATIONAL LABORATORY \\ Oak Ridge, Tennessee 37831-6283 \\ managed by \\ UT-BATTELLE, LLC \\ for the \\ US DEPARTMENT OF ENERGY \\ under contract DE-AC05-00OR22725
}

Approved For Public Release 
This page was intentionally left blank. 


\section{CONTENTS}

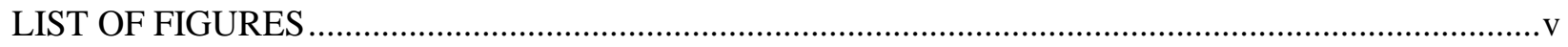

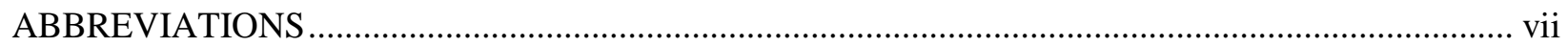

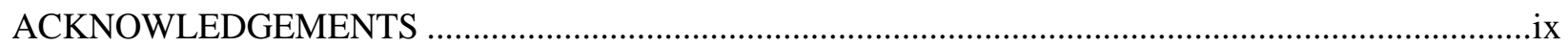

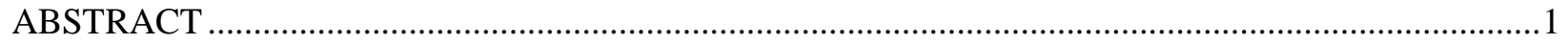

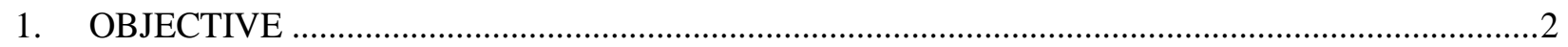

2. BENEFITS TO THE FUNDING DOE'S OFFICE MISSION …........................................................

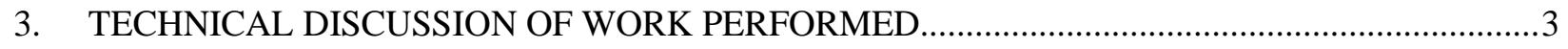

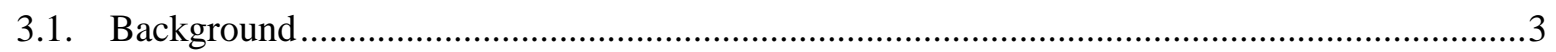

3.2. Activation and Properties of Lignin-derived Activated Carbon Fibers (LACF) ......................4

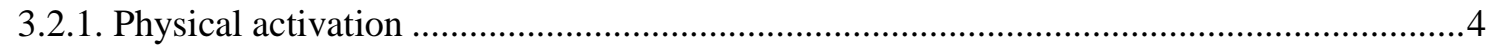

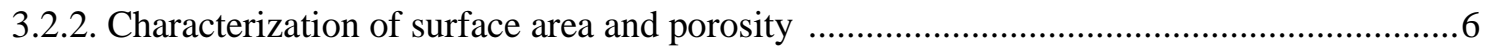

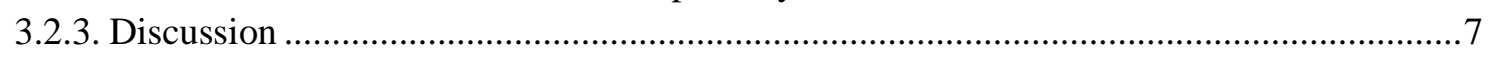

3.3. Adsorption Properties of Lignin-derived Activated Carbon Fibers (LACF) ............................ 8

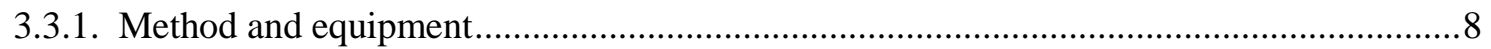

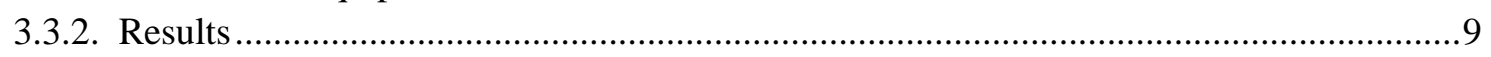

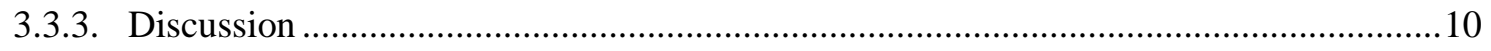

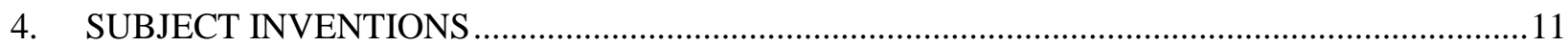

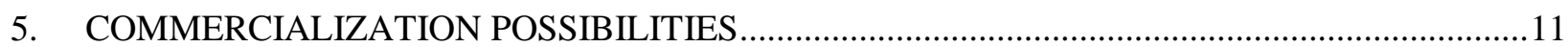

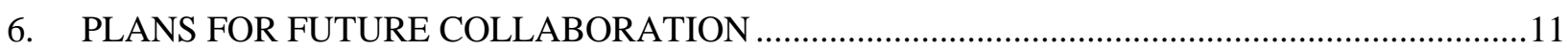

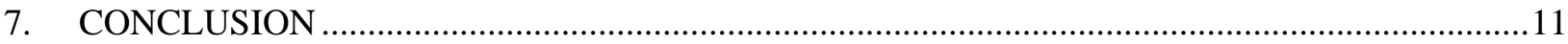


This page was intentionally left blank. 


\section{LIST OF FIGURES}

Figure

1 Fragment of raw lignin-based carbon fiber mat (a). Also shown are the tube furnace (b) and the alumina boat (c) used for activation.

The Autosorb AS-1C instrument used for characterization of surface area and porosity of LACF samples.

Nitrogen adsorption/desorption isotherms $(77 \mathrm{~K})$ of selected LACF samples and of reference pitch-based ACF (AP-400). Carbon dioxide adsorption/desorption isotherms (273 K) of selected LACF samples and of reference pitch-based ACF (AP-400)

Adsorption test rig and the adsorbent column $\mathrm{CO}_{2}$ adsorption breakthrough curves for material S-19-4 at $1000 \mathrm{ppm}$ inlet $\mathrm{CO}_{2}$ concentration..... $\mathrm{CO}_{2}$ adsorption capacities and BET surface areas for five different LACFs and

for a commercially available pitch-based ACF (AP-400) at $1000 \mathrm{ppm} \mathrm{CO}_{2}$ inlet concentration......

Page .5 .6 .7 7 .8 2

6


This page was intentionally left blank. 


\[ \text { ABBREVIATIONS } \]
activated carbon fibers
Brunauer - Emmett - Teller (method)
Climate, Controls and Security
carbon fiber composite molecular sieves
Carbon Fiber Technology Facility
Cooperative Research and Development Agreement
density functional theory (method)
electric swing adsorption
grand canonical Monte Carlo (method)
high efficiency particle arrester
indoor air pollutants
lignin-derived activated carbon fibers
lignin-based carbon fibers
non-local approximation density functional theory (method)
Oak Ridge National Laboratory
quenched surface density functional theory (method)
research and development
surface area
United Technologies Research Center
United Technologies Corporation
volume (pores)
volatile organic compounds


This page was intentionally left blank. 


\section{ACKNOWLEDGEMENTS}

This CRADA NFE-15-05496 was conducted as a Technical Collaboration project within the Oak Ridge National Laboratory (ORNL) Manufacturing Demonstration Facility (MDF) sponsored by the US Department of Energy Advanced Manufacturing Office (CPS Agreement Number 24761). Opportunities for MDF technical collaborations are posted in the announcement "Manufacturing Demonstration Facility Technology Collaborations for US Manufacturers in Advanced Manufacturing and Materials Technologies” at http://web.ornl.gov/sci/manufacturing/docs/FBOORNL-MDF-2013-2.pdf. The goal of technical collaborations is to engage industry partners to participate in short-term, collaborative projects within the Manufacturing Demonstration Facility (MDF) to assess applicability and of new energy efficient manufacturing technologies.

Research sponsored by the U.S. Department of Energy, Office of Energy Efficiency and Renewable Energy, Advanced Manufacturing Office, under contract DE-AC05-00OR22725 with UT-Battelle, LLC.

This phase 1 technical collaboration project (MDF-TC-2015-064) was begun on March 9, 2015 and was completed on January 31, 2016. The United Technologies Research Center is a large business. 
This page was intentionally left blank. 


\begin{abstract}
The object of this CRADA project between Oak Ridge National Laboratory (ORNL) and United Technologies Research Center (UTRC) is the characterization of lignin-derived activated carbon fibers (LACF) and determination of their adsorption properties for volatile organic compounds (VOC). Carbon fibers from lignin raw materials were manufactured at Oak Ridge National Laboratory (ORNL) using the technology previously developed at ORNL. These fibers were physically activated at ORNL using various activation conditions, and their surface area and pore-size distribution were characterized by gas adsorption. Based on these properties, ORNL down-selected five differently activated LACF materials and delivered them to UTRC for measurement of VOC adsorption properties. UTRC used standard techniques based on breakthrough curves to measure and determine the adsorption properties of indoor air pollutants (IAP) - namely formaldehyde and carbon dioxide - and to verify the extent of saturated fiber regenerability by thermal treatments. The results are summarized as follows: (1) ORNL demonstrated that physical activation of lignin-derived carbon fibers can be tailored to obtain LACF with surface areas and pore size distributions matching the properties of activated carbon fibers obtained from more expensive, fossil-fuel precursors; (2) UTRC investigated the LACF potential for use in air cleaning applications currently pursued by UTRC, such as building ventilation, and demonstrated their regenerability for $\mathrm{CO}_{2}$ and formaldehyde, (3) Both partners agree that LACF have potential for possible use in air cleaning applications.
\end{abstract}




\section{OBJECTIVE}

The object of this Cooperative Research and Development Agreement (CRADA) was the characterization of adsorption properties of lignin-derived activated carbon fibers (LACF) for formaldehyde (CHOH) and carbon dioxide $\left(\mathrm{CO}_{2}\right)$. Oak Ridge National Laboratory (ORNL) provided stabilized lignin fibers manufactured at the ORNL's Carbon Fiber Technology Facility (CFTF) using the technology previously developed at ORNL. These fibers were subsequently carbonized and physically activated in $\mathrm{CO}_{2}$ at ORNL. The lignin-derived activated carbon fibers (LACF) with various activation levels were characterized at ORNL by gas adsorption and their surface area and pore-size distribution were determined. Based on these properties, ORNL down-selected five differently activated LACF materials and delivered them to United Technology Research Center (UTRC) for measurements of VOC adsorption properties. UTRC used breakthrough curves measurements to determine the adsorption capacity of carbon dioxide and formaldehyde (two typical indoor air contaminants in buildings) and verified the extent of by which the original adsorption properties can be restored in a regeneration cycle. The results confirmed that LACF with properly selected characteristics can potentially be used for air cleaning applications currently pursued by UTRC.

\section{BENEFITS TO THE FUNDING DOE'S OFFICE MISSION}

The end goal of this project is evaluation of the effect of activation conditions and resulting physical properties on the adsorption performance of LACF. Lignin is a low-cost renewable resource and a byproduct of biorefineries and fiber and pulp industry, where it is currently regarded either as a waste or as a commodity material which is best used as fuel. At ORNL however, lignin is regarded as a material of high potential for value-added products through advanced manufacturing.

The Carbon Fiber Technology Facility (CFTF) is a highly innovative technology facility recently commissioned at ORNL by the U. S. DOE Advanced Manufacturing Office. CFTF offers advanced manufacturing lines for fabrication of carbon fibers and scaling up of emerging carbon fiber products. A central place in CFTF is the melt-spinning line designed for spinning lignin, pitch and polyolefins precursors in either tow or web forms. ORNL has evaluated diverse sources of lignin as potential feed stock for low-cost carbon fibers manufacture. ${ }^{1}$

In this CRADA project, a subset of lignin-based fibers manufactured in mat form at CFTF was converted at ORNL into LACF and tested for adsorption properties of $\mathrm{CO}_{2}$ and $\mathrm{CHOH}$. Currently, there is no other commercially available LACF, and a supply chain does not exist. This CRADA project proved that lignin fibers can be converted in a controlled manner to LACF with useful adsorption properties for carbon dioxide and formaldehyde.

The short term impact of this project is demonstration of LACF-based air purification technology, by quantification of removal efficiency for common indoor air pollutants at relevant concentration conditions. The results will strengthen future responses to federal funding opportunities and increase the likelihood of additional investments in this technology.

\footnotetext{
${ }^{1}$ http://energy.gov/sites/prod/files/2015/06/f22/R22-AMO\%20RD\%20Program\%20Review\%20-\%20GTI\%20DEEE0005779\%20Final.pdf
} 
The long term impact is the potential for significant energy savings in the buildings sector through optimization of ventilation schemes.

\section{TECHNICAL DISCUSSION OF WORK PERFORMED}

\subsection{Background}

Indoor air pollutants (IAP) are potential health hazards because of their cumulative exposure effect. ${ }^{2}$ Among these, formaldehyde is a major concern due to its carcinogenic character ${ }^{3}$. In addition, $\mathrm{CO}_{2}$ needs to be controlled in indoor environments in order to provide a productive working space ${ }^{4}$. HEPA filters are ineffective for removing chemical contaminants, unpleasant odors and $\mathrm{CO}_{2}$. Of all possible adsorbents for removal of chemical pollutants, high surface area carbon is the adsorbent of choice. Large industrial applications use packed beds of granular carbon, but these systems are not useful for adsorption of low IAP concentrations typical of indoor air. Furthermore, they are non-regenerable and require periodic replacement.

Attempts have been made to replace non-regenerable carbon filters with more efficient media that can be economically regenerated. The electric swing adsorption (ESA) developed at $\mathrm{ORNL}^{5}$ solved the regeneration problem by using carbon fiber monoliths made by bonding together ACF into a porous body which is air-permeable and electrically conductive. ${ }^{6,7}$ The heating caused by passing of an electric current through the monoliths induces thermodesorption of pollutants and regenerates the initial adsorption properties. ${ }^{8},{ }^{9}$ Although technically competitive, this technology could not be promoted on the market because the only ACF available at the time were pitch-derived carbon fibers available from a sole Chinese source at very prohibitive costs. A similar situation exists for all active filtration media, including activated carbon cloth, based on phenolic-, rayon-, and pitch-derived carbon fibers, which have been so far evaluated. ${ }^{10,11,12,13}$

\footnotetext{
2 J.M. Logue, T E McKone, M H Sherman, B C Singer, Hazard assessment of chemical air contaminants measured in residences, Indoor Air 21 (2011) 92-109.

${ }^{3}$ World Health Organization guidelines for indoor air quality, 2010 http://www.euro.who.int/_data/assets/pdf_file/0009/128169/e94535.pdf

${ }^{4}$ Allen, J., et al., The combined and independent effects of carbon dioxide, ventilation, and volatile organic compounds on the cognitive function of office workers in a green building. Environmental Health Perspectives, 2015. 123(10). http://ehp.niehs.nih.gov/wp-content/uploads/advpub/2015/10/ehp.1510037.acco.pdf.

${ }^{5}$ R. R. Judkins, T. D. Burchell, Electric swing adsorption gas storage and delivery system, U. S. Patent 5,972,077 (Oct. 26, 1999)

${ }^{6}$ T D Burchell, C E Weaver, B R Chilcoat, F Derbyshire, M Jagtoyen, Activated carbon fiber composite material and method of making, U. S. Patent 6,030,698 (Feb 29, 2000).

${ }^{7}$ T D Burchell, C E Weaver, B R Chilcoat, F Derbyshire, M Jagtoyen, U. S. Patent 6,258,300 B1 (Jul. 10, 2001).

${ }^{8}$ K A Wilson, T D Burchell, R R Judkins, U. S. Patent 5,827,355 (Oct. 27, 1998)

${ }^{9}$ R. R. Judkins, T. D. Burchell, $\mathrm{CO}_{2}$ removal from gas streams using a carbon fiber composite molecular sieve. http://www.netl.doe.gov/publications/proceedings/01/carbon_seq/3b1.pdf

${ }^{10} \mathrm{~J}$ Economy, M Daley, C Mangun, Activated carbon fibers - Past, present, and future; http://web.anl.gov/PCS/acsfuel/preprint\%20archive/Files/Merge/Vol-41_1-0001.pdf

${ }^{11}$ M A Sidheswaran, H Destaillats, D P Sullivan, S Cohn, W J Fisk, Energy efficient indoor VOC air cleaning with activated carbon fiber (ACF) filters, Build. Environ. 47 (2012) 357-367

${ }^{12}$ L. Luo, D. Ramirez, M J Rood, G Grevillot, K James Hay, D L Thurston, Adsorption and electrothermal desorption of organic vapors using activated carbon adsorbents with novel morphologies, Carbon 44 (2006) 27152725
} 
The end goal of this project is evaluation of lignin as a raw material for manufacturing LACF with useful $\mathrm{HCOH}$ and $\mathrm{CO}_{2}$ adsorption performance, finding of the activation conditions, and demonstration of a viable product based on LACF that can be used for air cleaning in building ventilation.

The United Technologies Research Center (UTRC) is the main research center for United Technologies Corporation (UTC), a US-based Fortune-500 company that provides high-technology products for commercial buildings and aerospace to customers around the world. Through its Climate, Controls and Security (CCS) division, UTC is a global pioneer in the buildings sector, and the world's largest provider of buildings technologies, climate systems, controls and automations, and fire and security solutions. CCS employs 120,000 employees at 74 sites in America, Asia and Europe, and 49 R\&D centers.

It has been estimated that implementation of air purification technologies in commercial buildings could save annually about $20 \%$ of energy for HVAC systems ${ }^{14}$. The successful completion of this CRADA project completely changes the cost - benefits equation for regenerable air indoor pollution filters. It is demonstrated that low-cost lignin fibers obtained from available bio resources can be converted into a LACF product with tailored adsorption properties that match and exceed those of more expensive, but economically unaffordable, ACF available from other sources.

\subsection{Activation and Properties of Lignin-derived Activated Carbon Fibers (LACF)}

\subsubsection{Physical activation}

A first challenge of this project was identification of process conditions by which lignin-based carbon fibers can be activated for adsorption of $\mathrm{CO}_{2}$ and $\mathrm{HCOH}$, with similar (or superior) performance as the pitch-derived ACF. Activation is done by controlled oxidation with hot $\mathrm{CO}_{2}$ of the fibers, which results in controlled development of narrow pores and significantly increases the total surface area. The target parameters for the activation step were BET surface area of $1500 \mathrm{~m}^{2} / \mathrm{g}$, total pore volume higher than 0.4 $\mathrm{cm}^{3} / \mathrm{g}$, and a large fraction (over $80 \%$ ) in micropores ( $<2 \mathrm{~nm}$ in size). Previous attempts at ORNL have shown that $\mathrm{CO}_{2}$ activation is feasible for lignin-based carbon fibers (LBCF), but a systematic study has not been done before this project.

Raw lignin fiber mats were procured from the CFTF production of melt-spun lignin fibers. The lot used in this project was stabilized at CFTF and carbonized at ORNL in protective nitrogen atmosphere. A photo of carbonized LBCF mat is shown in Fig. 1. This material was further physically activated at various conditions at ORNL.

Physical activation (conversion) of carbon fibers into LACF is based on the following oxidation reaction between carbon and carbon dioxide:

$\mathrm{C}_{(\mathrm{s})}+\mathrm{CO}_{2(\mathrm{~g})} \rightarrow 2 \mathrm{CO}_{(\mathrm{g})}$

This reaction was performed in a horizontal furnace provided with an alumina tube, 2 inches in diameter (Fig. 1b). About 4.5 - 5.0 g of carbonized mat was placed in an empty, pre-weighed alumina boat (Fig. 1c) and the boat was loaded in the tube furnace. A constant flow of $\mathrm{CO}_{2}$ gas was allowed through the

\footnotetext{
${ }^{13} \mathrm{H}$ An, B Feng, $\mathrm{S} \mathrm{Su}, \mathrm{CO}_{2}$ capture by electrothermal swing adsorption with activated carbon fiber materials, Int, $J$. Greenhouse Gas Control 5 (2011) 16-25

${ }^{14} \mathrm{http} / /$ /enverid.com/wp-content/uploads/2015/10/Novel-Air-Treatment-Technology-for-Reducing-HVAC-EnergyUse.pdf
} 
process tube. After the air was displaced by $\mathrm{CO}_{2}$ the temperature was ramped up to the desired process temperature. A series of LACF sample batches were obtained by varying the process temperature, the hold time at the process temperature, and the $\mathrm{CO}_{2}$ flow rate. The activation level, as expressed by the percentage weight loss relative to the original weight of LBCF, varied between 17 and 75 \% (Table 1).
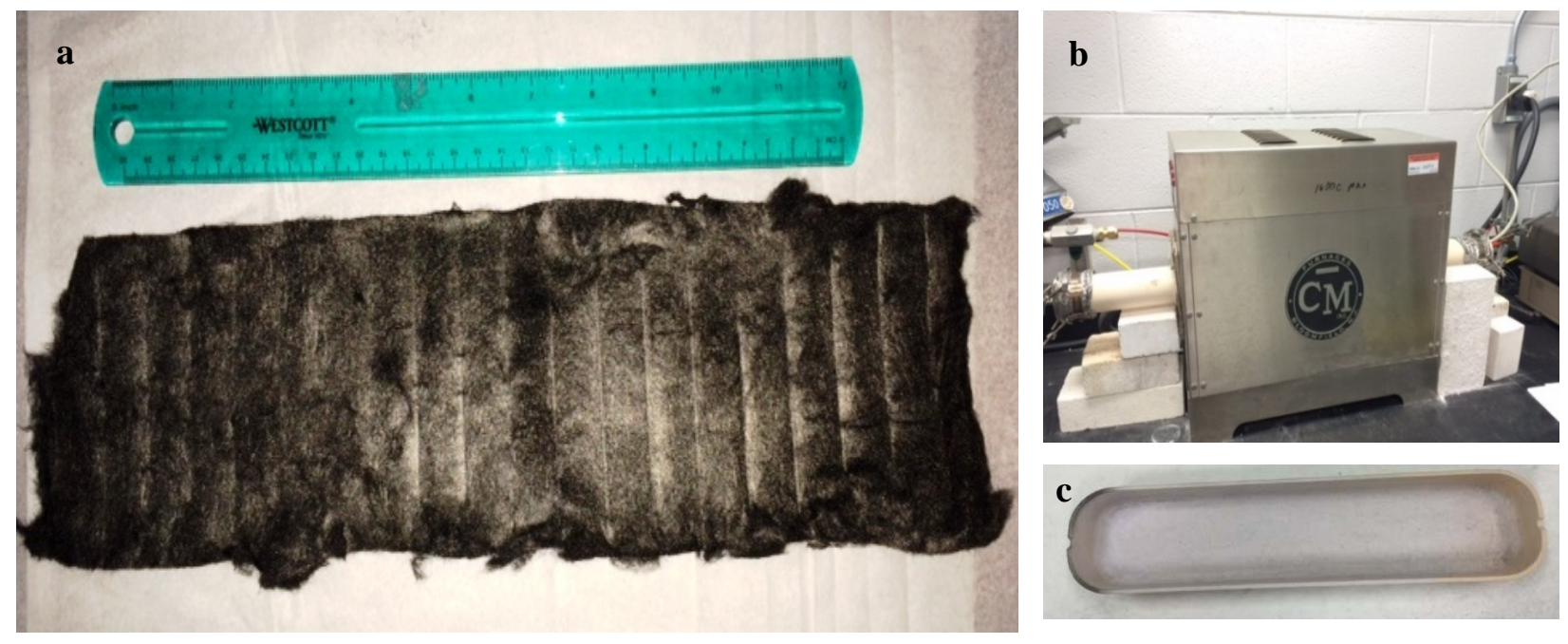

Figure 1: $\quad$ Fragment of raw lignin-based carbon fiber mat (a). Also shown are the tube furnace (b) and the alumina boat (c) used for activation.

Table 1: $\quad$ Summary of LACF samples and their physical properties (surface area and porosity)

\begin{tabular}{|c|c|c|c|c|c|c|c|c|}
\hline \multirow{3}{*}{$\begin{array}{c}\text { Sample } \\
\text { ID }\end{array}$} & \multicolumn{5}{|c|}{$\mathrm{N}_{2}$ analysis } & \multicolumn{3}{|c|}{$\mathrm{CO}_{2}$ analysis } \\
\hline & $\begin{array}{l}\text { Burn- } \\
\text { off }\end{array}$ & BET SA & $\begin{array}{c}\text { QS-DFT } \\
\text { SA }\end{array}$ & $\begin{array}{l}\mathrm{V}_{\text {total }} \\
\text { pores }\end{array}$ & $\begin{array}{l}\text { QS-DFT } \\
\mathrm{V}_{\text {micropores }} \\
<20 \mathrm{~A}\end{array}$ & $\begin{array}{c}\text { NL-DFT } \\
\text { Vultramicropores } \\
<7 \mathrm{~A}\end{array}$ & $\begin{array}{c}\text { NL-DFT } \\
V_{\text {narrow pores }} \\
<14 \mathrm{~A} \\
\end{array}$ & $\begin{array}{c}\text { GCMC } \\
\mathrm{V}_{\text {narrow pores }} \\
<14 \mathrm{~A}\end{array}$ \\
\hline & $\%$ & $\mathrm{~m} 2 / \mathrm{g}$ & $\mathrm{m} 2 / \mathrm{g}$ & $\mathrm{cc} / \mathrm{g}$ & $\mathrm{cc} / \mathrm{g}$ & $\mathrm{cc} / \mathrm{g}$ & $\mathrm{cc} / \mathrm{g}$ & $\mathrm{cc} / \mathrm{g}$ \\
\hline S-19-0 & 0 & 615 & 873 & 0.25 & 0.23 & 0.07 & 0.15 & 0.15 \\
\hline S-19-1 & 17 & 717 & 1007 & 0.28 & 0.26 & 0.17 & 0.26 & 0.24 \\
\hline S-19-4 & 23 & 944 & 1313 & 0.43 & 0.40 & 0.23 & 0.34 & 0.37 \\
\hline S-19-5 & 27 & 1191 & 1632 & 0.50 & 0.46 & 0.26 & 0.38 & 0.42 \\
\hline S-19-6 & 50 & 1626 & 2131 & 0.97 & 0.60 & 0.40 & 0.64 & 0.77 \\
\hline S-19-7 & 75 & 2630 & 3460 & 1.41 & 0.96 & 0.72 & 1.23 & 1.35 \\
\hline AP-400 & $\mathrm{n} / \mathrm{a}$ & 1702 & 1622 & 0.77 & 0.66 & 0.24 & 0.50 & 0.53 \\
\hline
\end{tabular}

Note: The bottom row shows properties of pitch-based ACF used as in previous studies at ORNL (sample AP400). The properties of this sample were selected as target of LACF prepared in this project. 


\subsubsection{Characterization of surface area and porosity}

The enabling properties for gas adsorption are the internal surface area and the porosity characteristics. Adsorption of nitrogen at $77 \mathrm{~K}$ was used to calculate total surface area by the BET method, ${ }^{15}$ total pore volume, and the pore size distribution using the method based on density functional theory in the quenched surface approximation (QS-DFT) ${ }^{16}$ for slit-shaped carbon pores. The total micropores volume $(<20 \AA)$ was estimated from these data. Adsorption at $\mathrm{CO}_{2}$ at $273 \mathrm{~K}$ was used to estimate the volume of narrow micropores $(<14 \AA)$ and of ultramicropores $(<7 \AA)$ using the density functional theory method in the non-local approximation (NL-DFT) for slit-shaped carbon pores. ${ }^{17}$ All measurements were done at pressures going up to 1 bar, using the Autosorb AS-C1 instrument (Quantachrome Instruments, Inc.) shown in Fig. 2. All calculations were performed using the Quantachrome ASiQwin software (version 2.0) available with the commercial instrument.

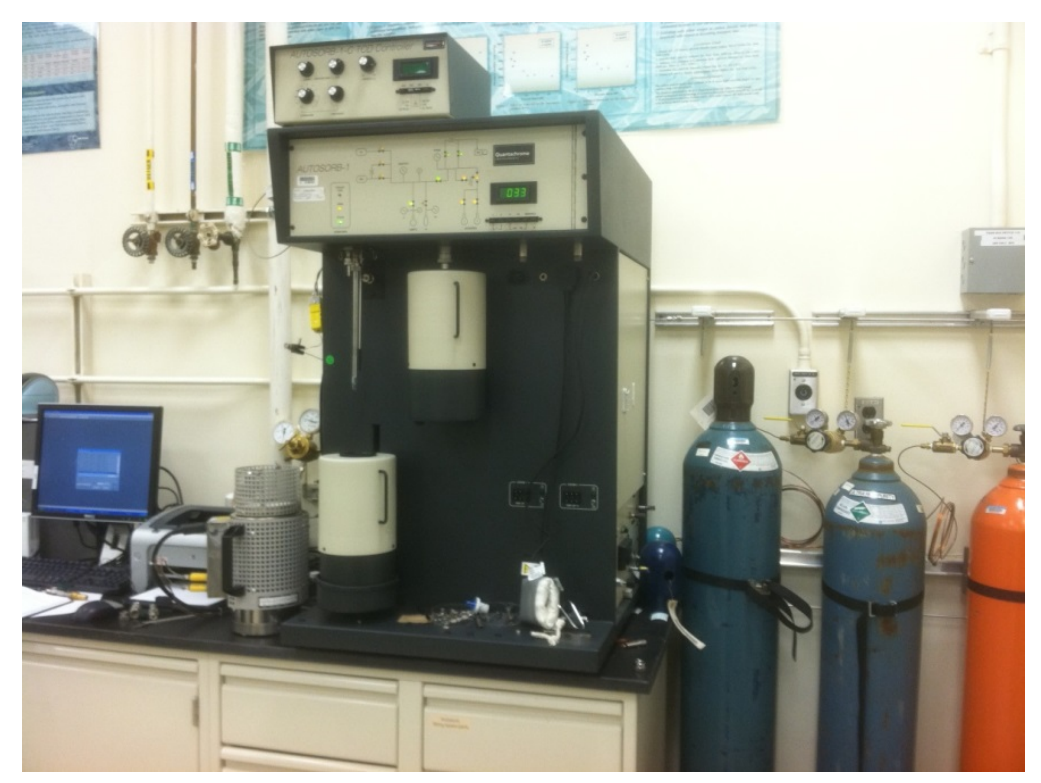

Figure 2: $\quad$ The Autosorb AS-1C instrument used for characterization of surface area and porosity of LACF samples.

The raw $\mathrm{N}_{2}$ and $\mathrm{CO}_{2}$ adsorption isotherms are plotted in Figure 3 and 4 and the characterization results are summarized in Table 1. Note the reference sample (AP-400) listed at the bottom of Table 1 is the pitch-based ACF available from China that was used in previous research at ORNL. The target of the current CRADA project was to reproduce and exceed the properties of this sample using lignin-derived precursors. The comparison of properties show that samples S-19-6 and S-19-7, with activation (burn-off) levels of $50 \%$ and $75 \%$ respectively, reached and outperformed the target properties of pitch-based ACF.

\footnotetext{
${ }^{15}$ S Brunauer, P H Emmett, E Teller, Adsorption of gases in multimolecular layers, J. Am. Chem. Soc. 60 (1938) 309-319

${ }^{16}$ P I Ravikovitch, A I Neimark, density functional theory model of adsorption on amorphous and microporous silica, Langmuir 22 (2006) 11171-11179

${ }^{17}$ P I Ravikovitch, A Vishnyakov, R Russo, A V Neimark, Unified approach to pore size characterization of microporous carbonaceous materials from $\mathrm{N}_{2}$, Ar and $\mathrm{CO}_{2}$ adsorption isotherms, Langmuir 16 (2000) 2311-2320
} 
Visual comparison between properties of LACF samples with sample AP-400 (Figs. 3 and 4) shows once again that high activation levels (50 and $75 \%$ ) are needed to reproduce and to exceed the porosity properties of the target AP-400 pitch-based ACF.

\subsubsection{Discussion}

The as-received sample (S-19-0) has moderate BET surface area $\left(615 \mathrm{~m}^{2} / \mathrm{g}\right)$ and a small pore volume $\left(0.25 \mathrm{~cm}^{3} / \mathrm{g}\right)$ distributed mainly in pores lower than $10 \AA$. For this sample the porosity is created by the gas released from lignin during carbonization at $1000{ }^{\circ} \mathrm{C}$. With these properties, it is expected that the carbonized LBCF has some adsorption properties by itself. Indeed, it adsorbs up to $7 \mathrm{wt} \% \mathrm{CO}_{2}$ at 1 bar and $273 \mathrm{~K}$, but this is very low compared with activated ACF.
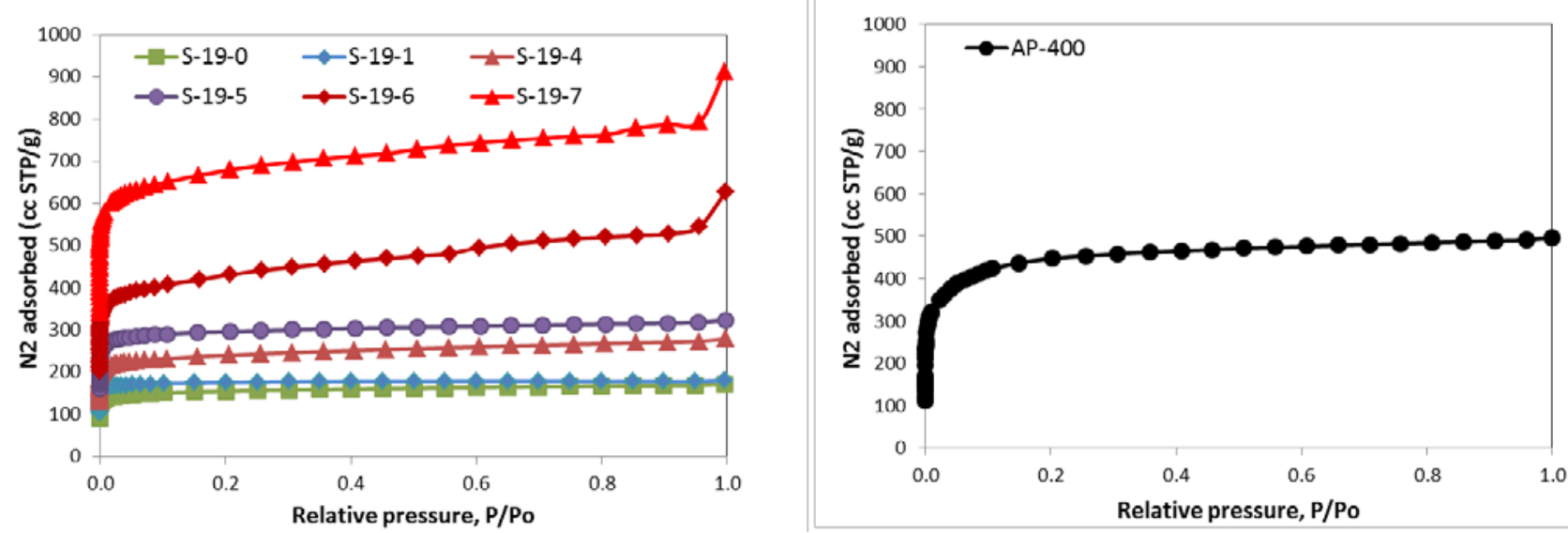

Figure 3: Nitrogen adsorption/desorption isotherms $(77 \mathrm{~K})$ of selected LACF samples and of reference pitch-based ACF (AP-400)
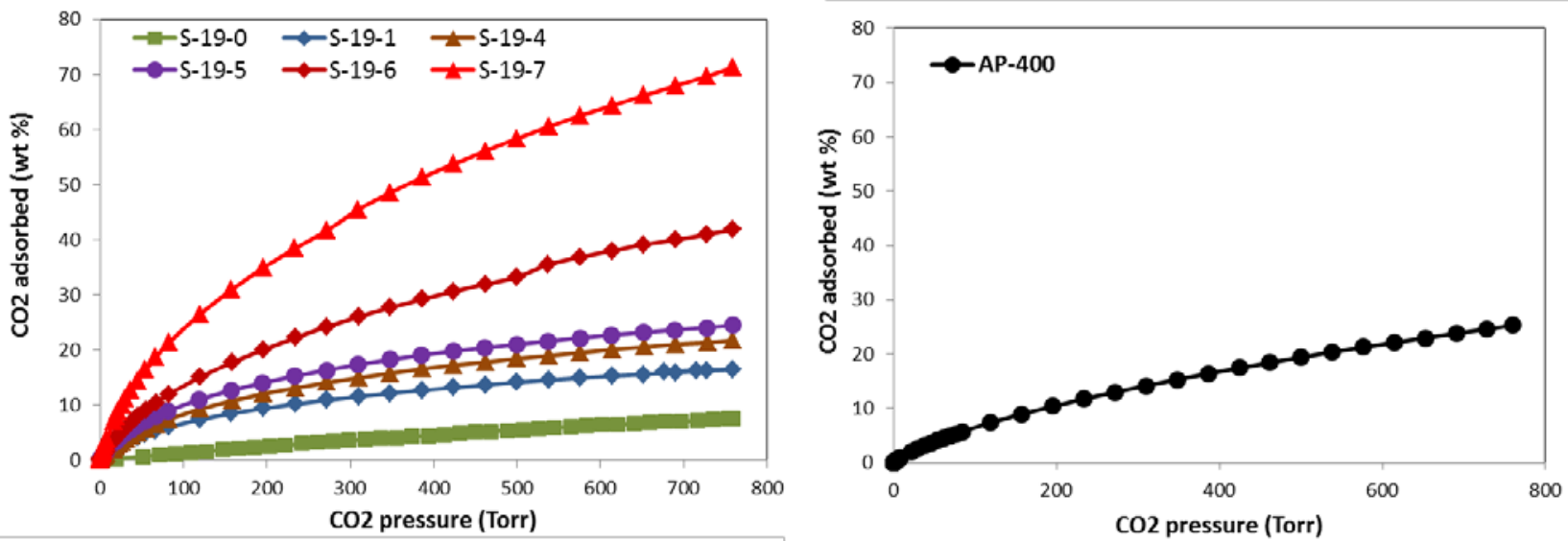

Figure 4: $\quad$ Carbon dioxide adsorption/desorption isotherms (273 K) of selected LACF samples and of reference pitch-based ACF (AP-400) 
Increasing the activation level causes the increase of surface area and pore volumes, and this enables higher adsorption of $\mathrm{N}_{2}$ at $77 \mathrm{~K}$ and $\mathrm{CO}_{2}$ at $273 \mathrm{~K}$. Sample S-19-5, with $27 \%$ activation level, has comparable $\mathrm{CO}_{2}$ uptake at $273 \mathrm{~K}$ as the pitch-derived reference AP-400. Samples S-19-6 (50 \% burn-off) and S-19-7 (75 \% burn-off) show almost two- and three times higher $\mathrm{CO}_{2}$ uptake in similar conditions. All samples are predominantly microporous, which is a great advantage for adsorption of small molecules. On highly activated samples, porosity extends apparently in the 10-20 $\AA$ range, but not as much as in the pitch-based sample.

All results show, globally, that $\mathrm{CO}_{2}$ activation is efficient for producing LACF with high adsorption potential. The properties can be tailored by changing the temperature, duration, and gas flow rate during activation in $\mathrm{CO}_{2}$. The target surface area and porosity values can be reached with moderate activation levels (about 25-30 \% weight loss). With higher levels of activation, the surface and porosity values increase constantly, and exceed the target figures at 50 and $75 \%$ weight loss. However, one should take in consideration that these two extremely activated fibers did not self-support themselves as a stable mat. The gain in surface properties comes at the price of low yield and weaker fibers.

\subsection{Adsorption Properties of Lignin-derived Activated carbon Fibers (LACF)}

The second challenge of this project was characterization of $\mathrm{CO}_{2}$ and VOC adsorption properties of LACF prepared at ORNL at low concentrations, comparable to those existing in polluted indoor air. This task was performed by UTRC, who has the equipment needed and has in the past developed methodology for VOC and $\mathrm{CO}_{2}$ adsorption measurements at low concentrations. Five LACF samples (about $2 \mathrm{~g}$ each) provided by ORNL were shipped UTRC for tests.

\subsubsection{Method and equipment}

UTRC used breakthrough curve measurements for evaluation of adsorption capacity for VOC (formaldehyde) and carbon dioxide. Both adsorption and desorption steps were measured in order to confirm the fibers regeneration capacity to the initial adsorption properties. Fig. 5 shows the adsorption test rig and the adsorbent column used for breakthrough tests.
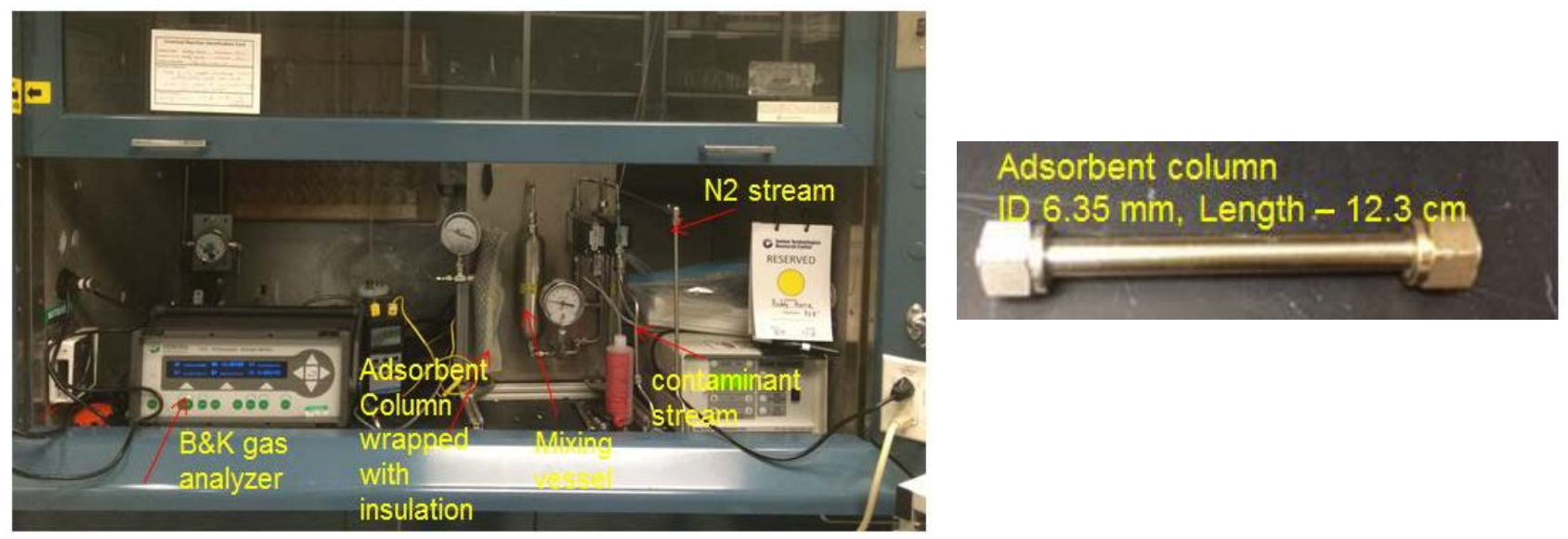

Figure 5: $\quad$ Adsorption test rig and the adsorbent column 
The as-received LACF samples were dried in an oven at $250{ }^{\circ} \mathrm{C}$ under vacuum. Samples were then ground and loaded in the adsorbent column. The breakthrough tests were performed with various concentrations of either $\mathrm{CO}_{2}$ or formaldehyde in a flow of nitrogen at room temperature. Both adsorption and desorption curves were measured to verify that desorption was achieved by a purge of clean nitrogen.

\subsubsection{Results}

Five consecutive adsorption/desorption cycles were performed on sample S-19-4 followed by room temperature desorption in $\mathrm{CO}_{2}$-free nitrogen. The breakthrough curves were sharp and reproducible (Fig. 6) showing that desorption at room temperature was complete. Sample S-19-4 had the highest capacities of all samples tested.

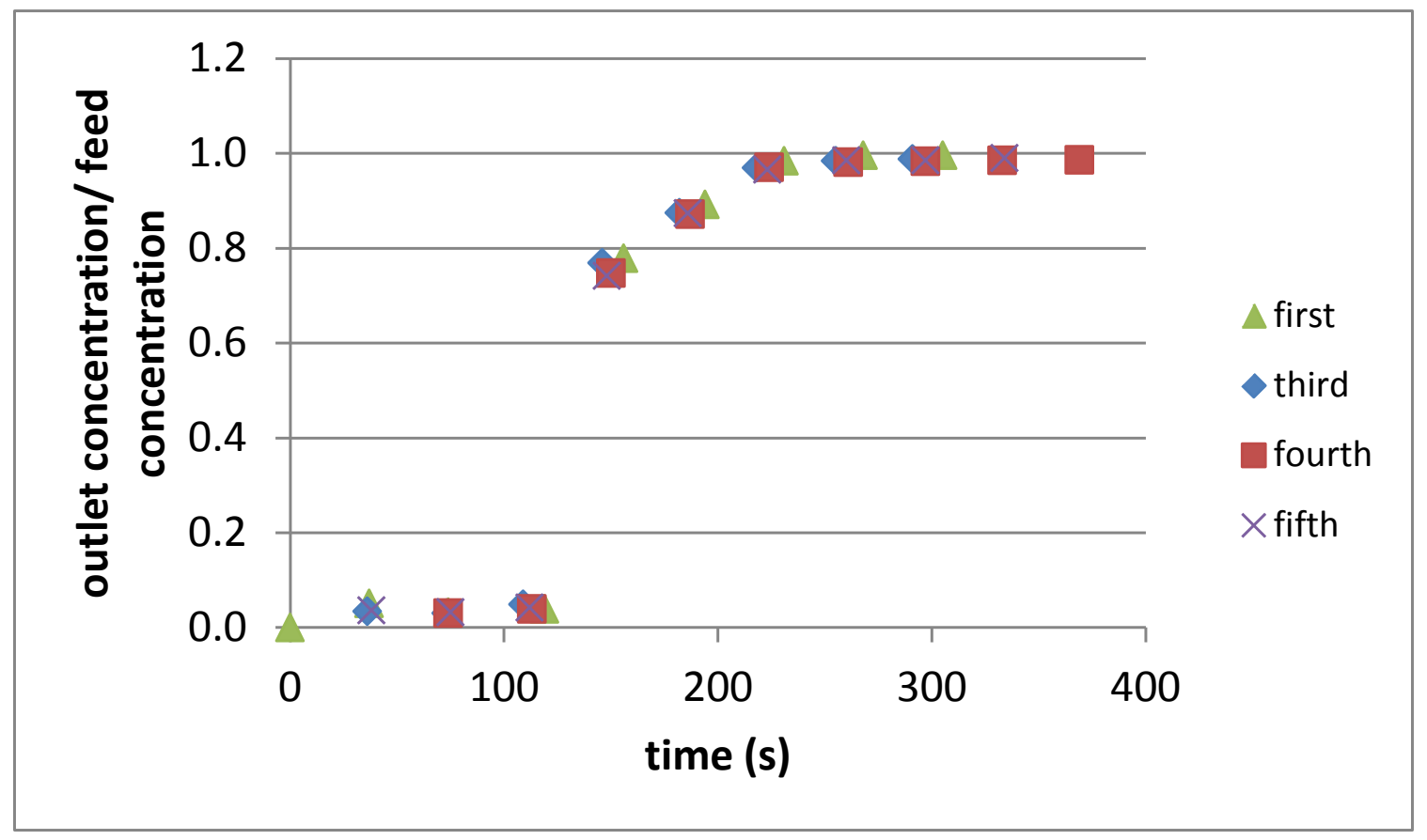

Figure 6: $\quad \mathrm{CO}_{2}$ adsorption breakthrough curves for material S-19-4 at 1000 ppm inlet $\mathrm{CO}_{2}$ concentration.

Figure 7 shows the $\mathrm{CO}_{2}$ adsorption capacities for the five LACF samples tested and their BET surface area. Also shown on the figure is the capacity and surface area of a commercially available ACF. The capacities are normalized by the highest capacity measured (i.e. S-19-4). The $\mathrm{CO}_{2}$ adsorption capacities were not proportional to the surface area or pore volume, which suggests that some surface chemistry is also at play in the process. The adsorption capacity of S-19-4 was seven times higher than measured for AP-400 and was significantly higher than reported on CFCMS by Burchell. ${ }^{18}$

\footnotetext{
${ }^{18}$ T.D Burchell, et al. A novel process and material for the separation of carbon dioxide and hydrogen sulfide gas
} mixtures, Carbon 35, (1997) 1279-1294 
The adsorption capacity of formaldehyde, a ubiquitous and particularly difficult to remove indoor pollutant was measured on S-19-4. The adsorption capacity was found to be in line with other sorbents tested at UTRC and reversible at room temperature, which offers sizeable advantage for commercial building application.

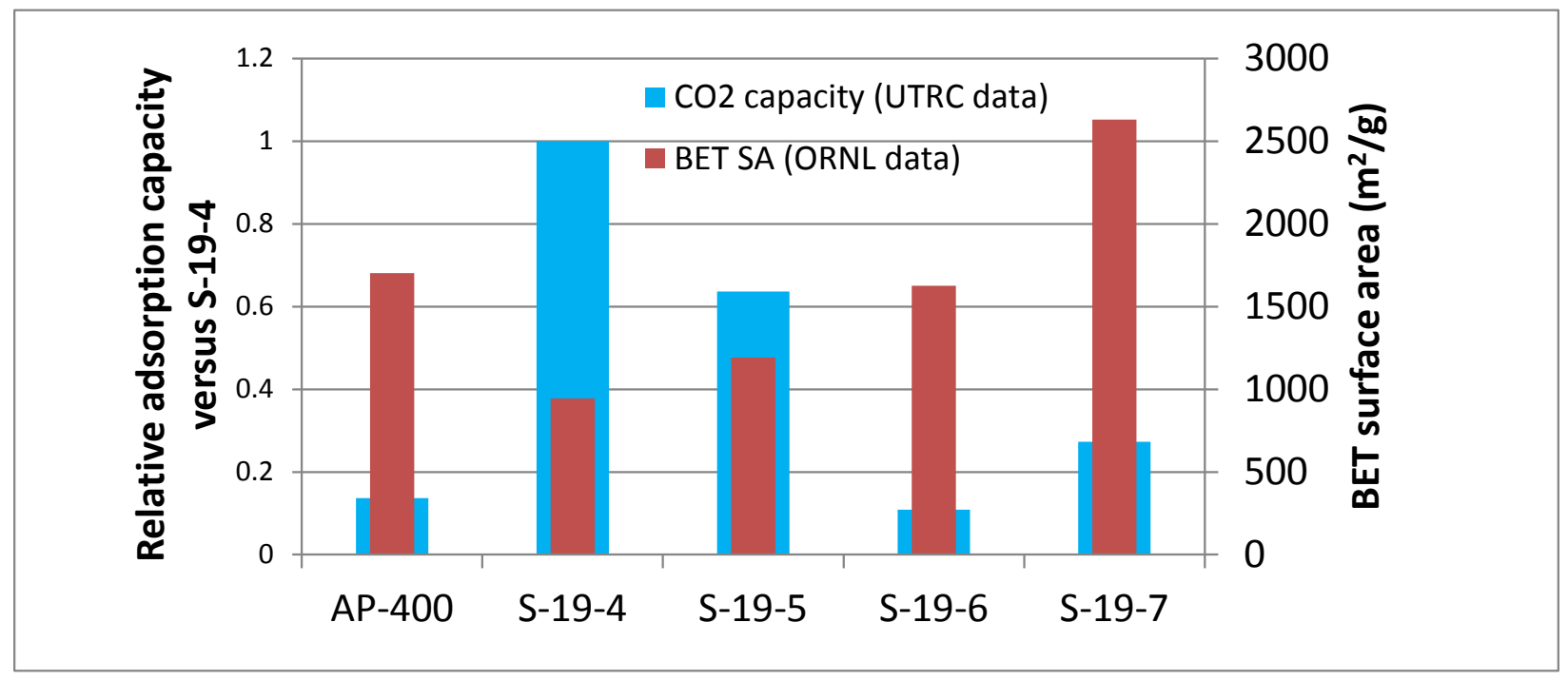

Figure 7: $\quad \mathrm{CO}_{2}$ adsorption capacities and BET surface areas for five different LACFs and for a commercially available pitch-based ACF (AP-400) at $1000 \mathrm{ppm} \mathrm{CO}_{2}$ inlet concentration.

\subsubsection{Discussion}

Many parameters factor into the acceptability of a sorbent for a particular task and the optimum combination of properties is task specific. For $\mathrm{CO}_{2}$ and VOC control in buildings, regenerability at low temperature with low energy input is paramount since energy consumption is the main driver for the application. Next, are the adsorption capacity (at low $\mathrm{CO}_{2}$ partial pressure) and the adsorption/desorption rates that will dictate the size and first cost of the system. Finally, the stability of the sorbent will influence the life cost for the system due to change out requirements.

The preliminary data obtained showed that the adsorption capacity of the LACF can be tailored by varying the process parameters during activation. The adsorption of $\mathrm{CO}_{2}$ and formaldehyde on the prepared materials at low concentrations needed for indoor air control was reversible at room temperature. The magnitude of the adsorption capacities made the materials worth investigating further as many additional aspects should be understood to accurately assess the value of the sorbent in a building application, for example, the effect of relative humidity, the effect of other contaminants and the extended life characteristics.

Material optimization should be carried out with respect to adsorption capacity and structural integrity since self-supporting fibers will have a much higher likelihood of commercialization. 


\section{SUBJECT INVENTIONS}

- Lignin-derived activated carbon fibers obtained by carbonization and physical activation of meltspun lignin fibers

- Lignin-derived activated carbon fibers for volatile organic compounds retention to be applied in air cleaning for commercial and residential building ventilation systems

The ORNL team has drafted invention disclosure for fabrication of LACF material. The UTRC team has drafted invention disclosures addressing the product integration of the material.

\section{COMMERCIALIZATION POSSIBILITIES}

The data obtained showed that LACF does reversibly adsorb $\mathrm{CO}_{2}$ and formaldehyde with a sizeable adsorption capacity. Complete regeneration can be achieved at room temperature with a sweep of contaminant free gas which provides a good basis for pollutant control in indoor environments.

Remaining gaps to improve commercialization potential of the material include:

- Further evaluation of the adsorption process such as

o Effect of humidity

o Competitive adsorption of other contaminants

o Extended life test with representative feed

- Development of cost effective scale up procedures (from g to kg)

- Implementation of the material in a filter component

o Optimize adsorption vs. fiber self-supporting ability

o Test as a fiber mat

- Component level implementation

o Adsorption/desorption cyclic operation

- $\quad$ System level implementation

\section{PLANS FOR FUTURE COLLABORATION}

As the material shows promise, the team is committed to seeking out additional funding from external sources to further its development and product integration.

\section{CONCLUSION}

The preliminary data obtained showed that the adsorption capacity of the LACF can be tailored by varying the process parameters during activation. The adsorption of $\mathrm{CO}_{2}$ and formaldehyde on the prepared materials at low concentrations needed for indoor air control was reversible at room temperature. The highest $\mathrm{CO}_{2}$ adsorption capacity measured at 1000 ppmv $\mathrm{CO}_{2}$ was $\sim 7$ times higher than that measured on a commercially available ACF and much higher than previously reported on CFCMS.

Therefore, the team recommends pursuing the experimental investigation of these materials in particular 
to understand the effect of relative humidity, the effect of other contaminants and the extended life characteristics. In parallel, scale-up of the material for cost effective integration into a HVAC component and system should be evaluated. 